\title{
O DESENHO DO MOVIMENTO NO PROCESSO DE CRIAÇÃO
}

\author{
Mônica Medeiros Ribeiro \\ Professora do Departamento de Fotografia, Teatro e Cinema da Escola de Belas Artes da Universidade \\ Federal de Minas Gerais \\ Doutora em Artes pela Universidade Federal de Minas Gerais \\ E-mail: monicaribeiro@yahoo.com
}

\section{Resumo}

Os estudos de processos de criação no âmbito das artes da cena têm lançado mão da crítica genética que estuda a obra de arte a partir do seu processo de construção. Lidar com essa memória, implica saber que o rememorar traz muito de invenção e esquecimento, portanto, não pode ser tomado como recuperação do que, de fato, aconteceu. A motivação dessa investigação foi o desejo de se conhecer o corpo em processo no percurso da criação da obra o As últimas flores do jardim das cerejeiras - inspirado na obra $O$ jardim das cerejeiras, de Anton Tchékhov, - do grupo Oficcina Multimédia, de Belo Horizonte. Trabalhamos com sete cadernos de artista da diretora lone de Medeiros para estudar o corpo em processo na referida obra. As imagens-desenhos registradas podem ser compreendidas como atos de invenção do real que possibilitam novas apropriações. Dizendo não à economia dos significados do ponto de vista da representação, busquei a construção de sentidos que a condição performativa do registro me possibilita. $\mathrm{O}$ registro que gesta um movimento de dança.

Palavras-chave

Desenho. Movimento. Registro. Processo de Criação.
Abstract

Studies on creative processes under the performing arts' scope have resorted to genetic criticism, that considers the piece of art since its construction process. Dealing with such memories involves knowing that the recollection brings about plenty of invention and forgetfulness, therefore, it cannot be taken as a recall of what actually happened. The motivation for this investigation was the will to understand the body in process under the course of creation of As últimas flores do jardim das cerejeiras (The last flowers of the cherry orchard) - inspired in The Cherry Orchard by Anton Chekhov - by the group Oficcina Multimédia, from Belo Horizonte. We have worked with seven artist notebooks of the group director lone de Medeiros to study the body in process in the given piece. Image-drawings registered may be understood as invention acts of the real which enable new appropriations. Saying no to the economy of meaning under the representation point of view, I sought the meaning construction that the performative condition of the register allowed me. The register which conceives dance movement.

Keywords

Design. Movement. Register. Creative Process. 


\section{Introdução'}

O processo de criação de espetáculos teatrais pode ser acompanhado presencialmente, como o fazem especialmente os dramaturgistas e pesquisadores de processos - no âmbito das artes da cena -, e investigado a partir de documentos primários como cadernos de artista, diários de bordo, vídeos, fotografias. Nessa segunda opção, tangenciamos a memória do processo. Lidar com essa memória, implica saber que o rememorar traz muito de invenção e esquecimento, portanto, não pode ser tomado como recuperação do que, de fato, aconteceu. Estudar os rastros dos processos leva ao contato com o rascunho, esse potente signo que nos diz de uma impressão sobre algo que passou. Impressão sobre impressão, nossa leitura dos rastros será sempre parcial e faltante. Disso parto para refletir sobre desenhos de movimento.

Os estudos de processos de criação no âmbito das artes da cena têm lançado mão da crítica genética que estuda a obra de arte a partir do seu processo de construção (Salles, 2004). Nascida em meio a rascunhos literários, na década de 1960, a investigação da gênese da obra de arte, por meio da crítica genética, ultrapassa o âmbito da literatura em direção às diversas linguagens artísticas nos anos 1980 (Budor; Grésillon; Mervant-Roux, 2013). ${ }^{2}$

$O$ interesse está posto na pesquisa a partir de vestígios, pistas, rastros dos processos de criação registrados nas diversas materialidades acima citadas. Traços da obra, como nos

\footnotetext{
1 Este texto faz parte dos resultados da pesquisa "O corpo
em processo: a performatividade dos registros na gênese da

1 Este texto faz parte dos resultados da pesquisa "O corpo
em processo: a performatividade dos registros na gênese da cena", financiada pela FAPEMIG, Edital Demanda Universal.

2 Aqui estamos abordando o estudo da gênese da obra por via da crítica genética, pois, conforme Féral (2013) o estudo da gênese existe desde as origens do teatro.
}

propõe Féral (2013, p. 570).

A palavra traço, e o conceito que ela cobre, me parecem mais de acordo com os modos de trabalho atuais. Ela é múltipla, polissêmica, exprime bem a diversidade da natureza e de origem dos traços possíveis. Eles podem ser, por exemplo, tanto sonoros quanto gráficos, tanto escritos quanto mnésicos, tanto virtuais quanto tangíveis, refletindo a multiplicidade dos dados que podem ser reunidos em torno da criação de um espetáculo. $O$ aspecto mais importante dessa classificação é a possibilidade de se ter traços virtuais ou invisíveis ou, ainda, ausentes. Com efeito, esse é um dos pontos fundamentais, me parece, que diferencia a genética literária da genética teatral.

Para a investigação aqui referida, trabalhamos com cadernos de artista da diretora lone de Medeiros $^{3}$. Buscamos identificar registros de movimentos por meio do desenho. Como nos aponta Cecília Salles (2004), esses registros - que funcionam como índices do processo de criação - são propícios à criação de teorias sobre o fazer. Por meio do seu estudo, podemos chegar a possíveis compreensões do pensamento do artista, de suas impressões, e, por vezes, de tendências da criação. Portanto, trabalhar sobre essas pistas não implica assertivas objetivas e certeiras, mas sim imaginações do devir obra. Esboços teóricos que se constituem a partir de vestígios do fazer da obra.

Ainda que Féral (2013) lance a questão acerca da necessária consciência de que, na genética teatral, se deve trabalhar sobre aquilo que foi suprimido no processo e, desse modo, a memória e observação dos ensaios se fazem imprescindíveis, tenho trabalhado a par-

3 lone de Medeiros é diretora do grupo Oficcina Multimédia (Belo Horizonte, MG) há 40 anos.

Ribeiro // O Desenho do Movimento no Processo de Criação Rev. Cena, Porto Alegre, n. 22, p. 166-176, jul./out. 2017 Disponível em: http://seer.ufrgs.br/cena 
tir de alguns dos pressupostos da crítica genética para investigar registros de processos de criação em cadernos de artista. Sabemos com Fahd Kaghat (2013) que esses registros não substituem a encenação e os movimentos e afetos do processo, mas eles nos conferem pistas sobre o pensamento imagético da artista diretora que, a seu modo, buscou materializar suas impressões dos ensaios sob a forma de desenho e letra.

A motivação dessa investigação foi o desejo de se conhecer o corpo em processo no percurso da criação do espetáculo As últimas flores do jardim das cerejeiras - inspirado na obra O jardim das cerejeiras, de Anton Tchékhov - do grupo Oficcina Multimédia de Belo Horizonte ${ }^{4}$. A metodologia desenvolvida para essa pesquisa parte dos pressupostos da crítica genética para analisar registros sob a forma de desenho de movimento. Cecília Salles (2008) nos auxilia quando estabelece uma analogia entre os registros e índices de pensamento do artista criador e, mais, quando sublinha a necessidade de se encontrar modos de leitura desses. Desse modo, ela parece sugerir que cada tipo e contexto de registro demanda um modo de leitura particular. Com isso não buscamos sistemas de análises de registros já construídos, mas deixamo-nos afetar pela potência de movimento que o desenho gesta.

A aparente condição fixa do registro é posta em questão quando se considera o entorno do desenho como parte importante a ser interpretada. Esse nos fornece o contexto do registro. O não desenhado está por vezes escrito, referenciado, constituindo-se parte dos vestígios e suscitando novos sentidos. Assim, nossa leitura pautou-se no traço sob a forma de desenho

4 Site do grupo: http://oficcinamultimedia.com.br/v2/ e sob a forma de letra.

Outro pressuposto importante que a crítica genética, por Salles (2008), nos apresenta é a necessidade de se escapar da busca pela origem da obra nesse estudo da gênese e considerar a presença de tendências, rumos vagos, direções. Assim, não nos interessou estudar o desenho com o objetivo de encontrar o movimento original. Buscamos, pela observação do registro, analisá-lo para posterior corporificação sob a forma de outro movimento. Além disso, há que se considerar, a respeito de qualquer observação que se faça, o que nos diz Paul Valery (2012, p. 23), em Degas dança desenho, "É verdade, todavia, que uma coisa é ainda mais instrutiva: a espantosa inexatidão provável da observação imediata, a falsificação que é a obra de nossos olhos. Observar é, em grande parte, imaginar o que esperamos ver". Observar deixando-se afetar, é, desde já, assumir-se como um leitor-criador dos rastros observados. Assim, podemos dizer que há parte de nós no que vemos, sendo possível, justamente por isso, a posterior corporificação e "re-invenção" do movimento pela dança.

Foram estudados sete cadernos de artista - datados de 2008 a 2012 - referentes aos processos de criação, ensaios, do espetáculo citado anteriormente. Após uma leitura skimming, foram marcadas todas as páginas que continham desenhos de movimentos. Os cadernos continham referências de livros, filmes, contatos de pessoas relacionadas ao processo criativo, observações de ensaio, questões propositivas, descrição de movimentos, emoções e ações que deveriam ocorrer na cena, objetos utilizados, desenhos, entre outros elementos, que possibilitaram impressões de parte do processo de criação. Encontramos um total de 390 páginas com desenhos de movimentos, 
das quais foram separadas 168. As imagens foram escolhidas em razão de sua potência de afecção. Quais imagens me provocavam, gerando-me desejo de movimento?

Os desenhos foram interpretados, mais que analisados, buscando evidenciar a relação entre eles e não sua essência. Busquei compreender o que a imagem me pedia, qual movimento ela me solicitava, me instigava. Pois, o desenho inquieta, "abre um pensamento" (Huberman, 1998, p. 10). O desenho nos pergunta: - E aí? Numa espécie de exercício de tradução, a criação operou papel decisivo na escolha dos desenhos, pois interessava aquele que me movia em direção a outros movimentos. Portanto, observei a ocorrência de pensamentos e sentimentos para construir uma argumentação acerca desses vestígios desenhados. Os desenhos de movimento foram tomados como índices do corpo em processo nos cadernos de artista da diretora lone de Medeiros, como se vê a seguir.

Figura 1: Gueixas das Últimas flores do jardim das cerejeiras.

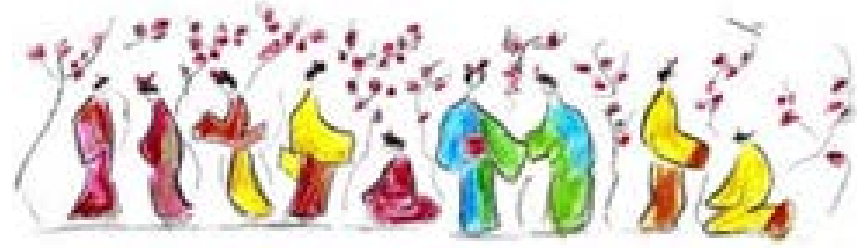

Fonte: Medeiros, 2010.

O jardim das cerejeiras, de Medeiros, ocorre num labirinto no qual o público entra para ver as cenas que ocorrem em cima e fora dele. As paredes do labirinto são de tela e nelas são projetadas imagens de vídeo que atravessavam os corpos dos espectadores e dos atores, instalando uma sequência de camadas de sentido. Como o labirinto de emoções no qual se perde Liubov - personagem feminina da obra de Tchékhov -, o cenário permite que as cenas ocupem lugares distintos, muitas vezes simultaneamente. O jogo de luz faz com que os personagens apareçam e desapareçam. A atmosfera é de sonho e memória. Dividido em três partes, o espetáculo inicia-se com minotauros cortando cerejeiras em alusão à brusca interrupção de uma era de requinte e privilégios da nobreza. Na primeira parte, imagens simbolizam as perdas inesperadas; na segunda, Liubov perde-se em suas emoções e busca encontrar uma saída por meio do fio de Ariadne; na terceira, parte do labirinto é aberta ao público e esse assiste as cenas que ocorrem em cima do cenário. Sentados ou deitados em um chão de plástico-bolha experimentam sensações sinestésicas - áudio- visuo-tátil - e assistem à dança de gueixas que simbolizam a possibilidade de um recomeço pela arte, metaforizando a beleza estética que favorece o advento de uma nova era.

Nesse espetáculo, os corpos e seus deslocamentos ocupam o lugar da palavra. Imagens sobre imagens superpostas aos corpos em ação nos dizem de uma cena multifacética, na qual música, audiovisual e dança compõem a trama discursiva.

Figura 2: Cenário de As últimas flores do jardim das cerejeiras (visão superior)

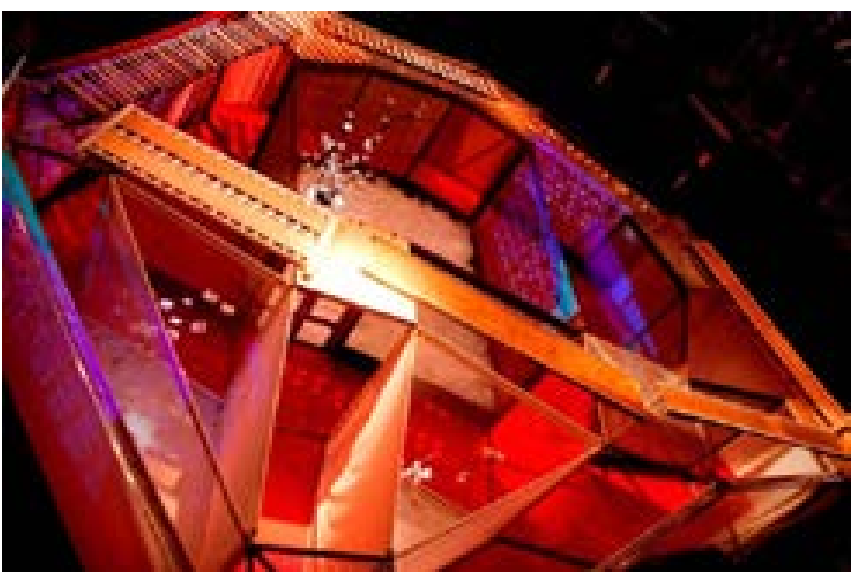

Fonte: Marco Aurélio Prates, 2010. 


\section{A performatividade do desenho}

Olhar para os desenhos buscando perceber sua capacidade inventiva, presente no instante da imagem, é conferir peformatividade ao registro. A partir do momento que John Searle, Jacques Derrida, Judith Butler, Gilles Deleuze ampliaram a noção de performatividade - conceito cunhado por John L. Austin em How to do things with words, na William James Lectures, em 1955 - para além do campo linguístico, incluindo os domínios da cultura em geral, pode-se pensar na letra performativa, nas imagens performativas. As imagens registradas podem ser compreendidas como atos de invenção do real que possibilitam novas apropriações.

John Austin (1990) performatizou a palavra ao conferir performatividade a algumas expressões na sua conhecida teoria dos atos de fala. Nela, ele diferencia sentenças constatativas de sentenças performativas. As sentenças performativas agem. Desse modo, ele considerou "a linguagem como ação, como forma de atuação sobre o real, e, portanto, de constituição do real, e não meramente de representação ou correspondência com a realidade" (Austin, 1990, p. 10). Mais interessante e importante ainda foi o fato de, com essa proposta teórica, Austin (1990, p. 11) propor, "uma concepção de linguagem como um complexo que envolve elementos do contexto, convenções de uso e intenções dos falantes".

Interessa-nos de suas proposições o fato de algumas sentenças serem consideradas correlacionadas a atos e a importância conferida às circunstâncias da fala. Desse modo, ao considerarmos o desenho análogo à sentença performativa de Austin, seu estudo interpretativo, em sua performatividade, pautou-se no movimento do traço, na circunstância do ves- tígio - o contexto da página e as informações e digressões lá presentes - e fez do desenho ato, fez do desenho dança.

Notamos a seguir o movimento do desenho que parece agir no instante, desde já performando-o. $O$ traço traz mobilidade e parece que vemos uma pessoa voltada para baixo balançando a saia.

Figura 3: Pessoa sentada.

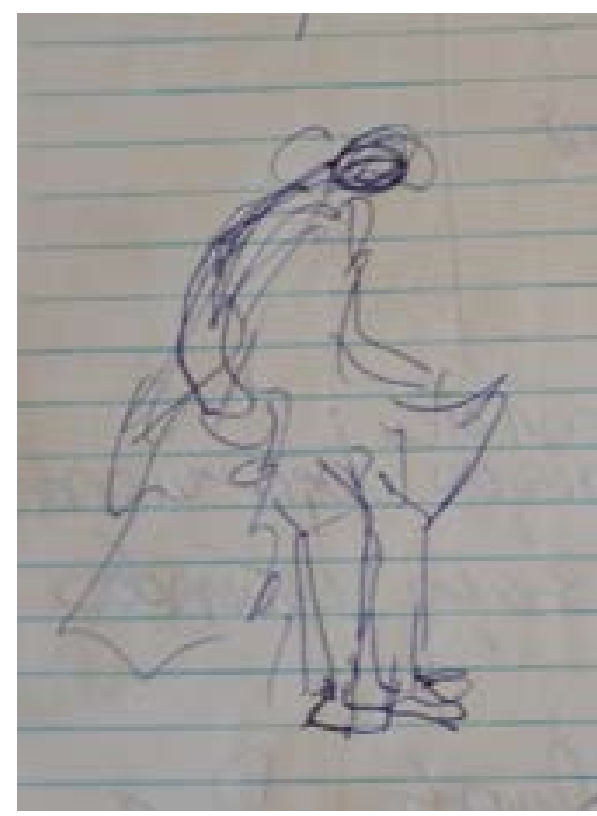

Fonte: Medeiros, 2010

Ainda que seja virtualmente, resta no desenho algo do movimento, um rastro. E importa dizer que não tratamos de copiar o desenho, representando-o com fidelidade. $O$ desejo foi trabalhar na poeira do movimento, naquilo que emerge do que se assentou como rastro. Assim, lidei com outros sentidos além de um suposto sentido recuperado. Com Boehn (2015, p. 32) lembramos que a "imagicidade não depende em nada do objeto representado. As imagens não são simples representações demonstrativas de uma significação já construída em outro lugar, são ao contrário mostrações originárias". O desenho dança, diz de si mais que daquele movimento que pode ter sido feito para representar. Portanto, não quis 
descobrir o movimento escondido na imagem do desenho, mas experimentar movimentos como desdobramentos da imagem.

Dizendo não à economia dos significados do ponto de vista da representação, busquei a construção de sentidos no agora, que a condição performativa do registro me possibilita. $O$ registro que gesta um movimento de dança. O registro performa o movimento de "origem", e, em seguida é performado pelo ato de dançá-lo. Os desenhos apresentam certa iterabilidade, no sentido de Derrida (1991), o que implica a possibilidade de serem repetidos em diferentes contextos. A iterabilidade comporta repetição, mas com deslocamento de sentido. Esse tipo de repetição, atravessado pela mudança, interessa na medida em que buscamos uma performatividade que transforma (Derrida, 1991).

Então podemos pensar em três dimensões do movimento referente: o movimento copiado - aquele da sala de ensaio; o movimento desenhado - o registro; e o movimento corporificado na forma de dança. O movimento copiado é o ausente. Apresenta-se como lacuna, brecha potente para criação. Não temos acesso a ele por via do estudo dos cadernos da artista. Entretanto ele é representado pelo movimento desenhado. $\mathrm{O}$ desenho traz algo do ausente, $\mathrm{o}$ que não implica sua presença plena. No movimento desenhado convivemos com o movimento ausente e presente simultaneamente. Ausente porque passado, e presente no traço que porta impressões. O movimento corporificado na forma de dança é o devir do desenho, seu sonho, sua transformação. Percorrer essas dimensões implica repetições com transformações.

A iterabilidade supõe uma restância mínima (como uma idealização míni- ma, embora limitada), para que a identidade do mesmo seja repetível e identificável em, através e até em vista da alteração. Porque as estruturas da iteração, outro traço decisivo, implica, ao mesmo tempo, identidade e diferença (Derrida, 1991, p. 76-77).

Foi interessante observar essa dualidade - identidade e diferença - em relação ao movimento desenhado. Se, por um lado, o movimento corporificado se diferenciava do desenhado, por outro, trazia certas características dele. O desenho a seguir, por exemplo, apresenta um corpo deitado de bruços no sofá com um braço estendido ao longo e acima da cabeça e outro "caindo" do sofá. Além disso, temos, no contexto da página, uma descrição do referido movimento: "deitado de bruços no sofá".

Figura 4: Deitado no sofá.

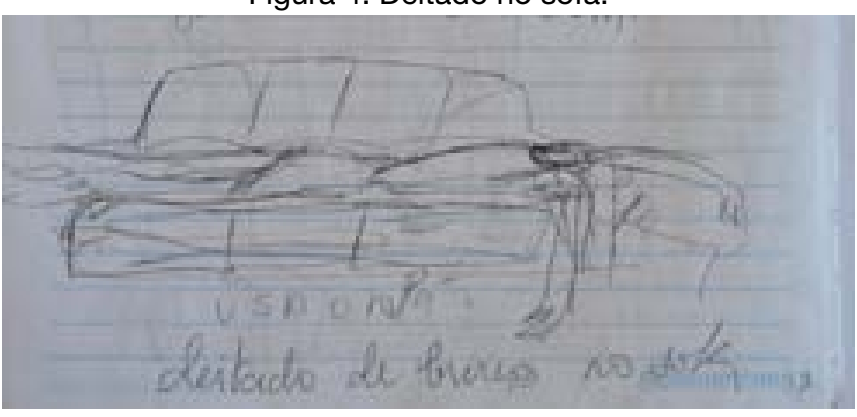

Fonte: Medeiros, 2011.

No momento de performar o desenho, o movimento foi realizado em pé, na posição ereta, já modificando por completo o contexto do movimento desenhado. Assim, podemos nos lembrar de outro conceito de Derrida (1991): a citacionalidade, que diz da condição de um signo ser retirado de seu contexto e trabalhado em outro, podendo apresentar significados diversos. A verticalidade obrou sobre a horizontalidade transformando o sentido estético do movimento. Trabalho com o espaço criado pelo movimento: nível, direção, eixo. Iterabilidade e citacionalidade se complementam criando um 
terceiro. Repetição com diferença. O mesmo sendo outro. Um corpo estendido no sofá, pesado e despojado deu lugar a um corpo em pé com braço estendido acima da cabeça. A sensação de despojamento e peso permaneceu. $\mathrm{O}$ registro performado sob a forma de movimento corporificado é o efeito da interpretação do vestígio de um "outro". O desenho nos fala de uma ausência prenha de presença. Aquele movimento que não está ali, mas, ao mesmo tempo, foi registrado resta invisível, imaginado. Resta memória, possibilidade de invenção.

\section{Sobre o desenho do movimento}

Podemos pensar que os olhos e mãos de Medeiros estão em conexão para desenhar o movimento percebido na sala de ensaio. Mãos e olhos são convocados no ato de desenhar, conforme sugere Inês Almeida (2002). Visão e tato interligados no desenhar - conexão multissensorial - que materializa o desenho no caderno da artista.

Figura 5: Em contato.

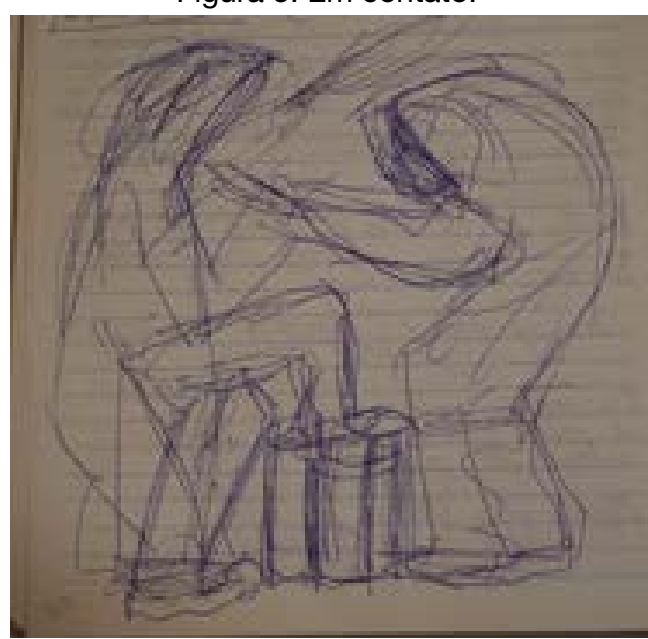

Fonte: Medeiros, 2012.

Observar o desenho, acompanhando-o com o olhar. Observar o desenho, imaginando-o em movimento. Observar o desenho, percebendo em mim, cinestesicamente, o movimento por ele gestado. Então passo a corporificá-lo internamente. Trata-se de uma simulação que porta invenção, mas é pautada pelo reconhecimento dos traços. Essa simulação ocorre internamente acionando parte das regiões cerebrais que são acionadas durante o movimento visível. Como um outro, o desenho dialoga comigo e me pede um movimento a partir da ausência que ele porta. Convivem nessa experiência o conhecido e o desconhecido. Reconheço o movimento pelo desenho e, ao performar o traço, ocorrem-me desdobramentos inventivos.

Trata-se de uma performance que transforma, redesenhando e construindo novo espaço de dança. A espacialidade - essa relação entre eu e o espaço que se configura na medida em que me movo - se faz lugar por ser espaço para enunciação de si por meio da dança. $O$ movimento corporificado é aqui deslocamento que constrói lugares possibilitando uma criação autoral. A autoralidade na movimentação foi um dos objetivos propostos nessa experiência. A partir de um registro criar outros movimentos. O autoral refere-se aqui à marca do sujeito que confere assinatura aos movimentos. Essa autoralidade, que implica o sujeito na criação, sugere lugares que falam de novas articulações do corpo que também trazem os restos do movimento ausente, mas incorporam devires outros.

A percepção das direções e a intensidade dos traços do desenho permitem-me trazer a imagem visual para meu próprio corpo que simula o que vê. Ao executar o movimento, em sua nova configuração, a espacialidade é explorada de modo a retirar o movimento de sua condição de instante e trabalhar na duração.

O jogo com a temporalidade é outro ponto fundamental aqui. A translação do instante 
para a duração é parte do performar o desenho. O traço performativo que gesta novos movimentos é operado no tempo por essa translação. Obrar na duração é concomitante à experiência de espacialidade, dado que não há experiência de tempo isenta da espacialidade.

\section{O corpo do desenho}

Ao observar os desenhos registrados durante o processo de $A$ última flores no jardim das cerejeiras percebemos, por meio de traços rabiscados, corpos voltados para o chão. $O$ rabisco dá ideia de movimento e sugere que o movimento copiado fora capturado em meio ao deslocamento no espaço-tempo. A impressão é que não se deu um registro de uma pausa em um movimento, mas sim a captura do efêmero. $O$ fato de grande parte dos movimentos apresentarem corpos curvados em direção ao chão denota gestos concêntricos e uma ênfase tônica no centro do corpo.

Figura 6: Carpideiras:

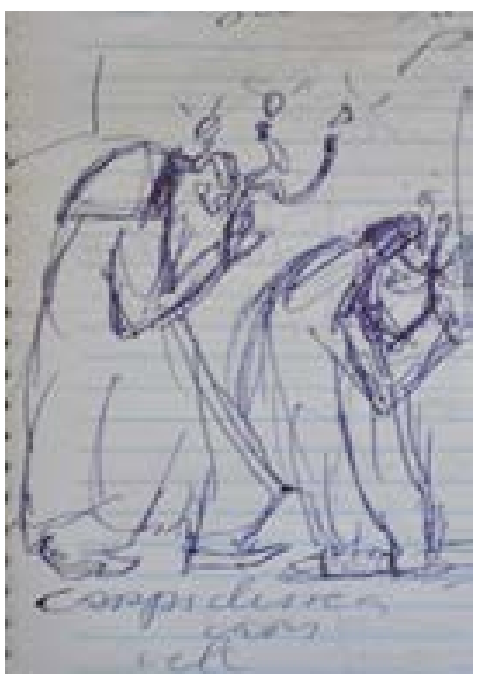

Fonte: Medeiros, 2012.

Que corpo é esse que se desloca no labirinto do Jardim das Cerejeiras, de Medeiros?
A presença desses desenhos, nos cadernos de artista, deixa transparecer certo pensamento de corpo. Nos cadernos, as inclinações e o contexto do desenho nos dizem de corpos que deitam, que carregam velas, que manipulam bonecos, que dialogam em par, se esforçam, limpam o chão. Corpos que não se deixam ver plenamente. Já na cena, corpo velado, que passa por entre telas, deixando-se ver atravessado por imagens projetadas. Assim, corpos que portam múltiplos sentidos, esses percebidos pelas projeções, pelas inclinações, pelos vestuários, pelos deslocamentos e desenhos do movimento no espaço tempo.

Pensamentos, impressões de corpos promovidas pelos desenhos dos cadernos não chegam a definir um modelo de corpo. Aqui se percebe que, na cena, o corpo é entretecido com imagens e constitui-se parte da materialidade cênica. No caderno, o corpo ganha movimento pelo traço-rabisco e o contexto da página. Sempre corpos velados e traspassados por imagens.

Outra possibilidade é pensar por imagens. Nesse modo cognitivo pretendemos ir além da representação e, pelo olhar atento ao contexto da página, principalmente, imaginar o que ali não está. Informação virtual. Pura potência que o silêncio, o vazio, o não dito permitem desenvolver sob a forma de articulação de ideias - pensamento - e sentimentos. Associamos pensamento e sentimento para sublinharmos que razão e emoção estão juntas na elaboração cognitiva.

Assim, apresento uma sequência de imagens-desenho para que o leitor possa configurar sua própria impressão do corpo em As últimas flores do Jardim das Cerejeiras. 
Figura 7: Cansaço.

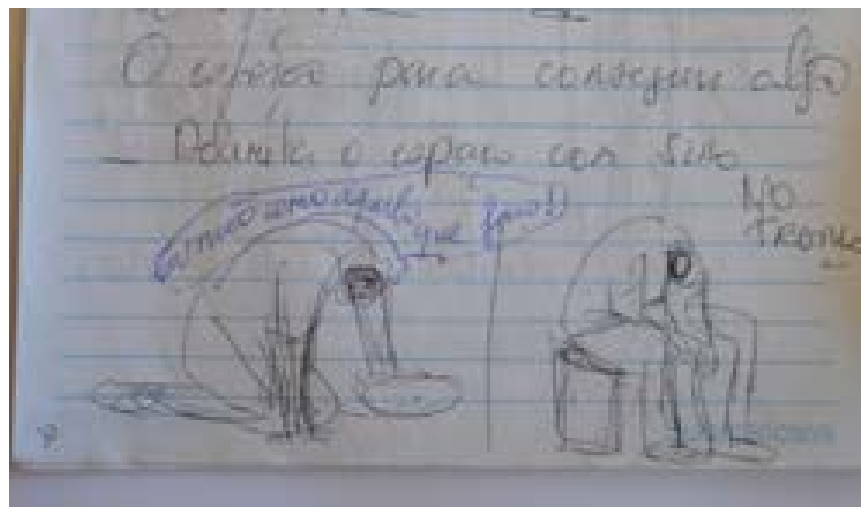

Fonte: Medeiros, 2011.

Figura 8: A manipulação.

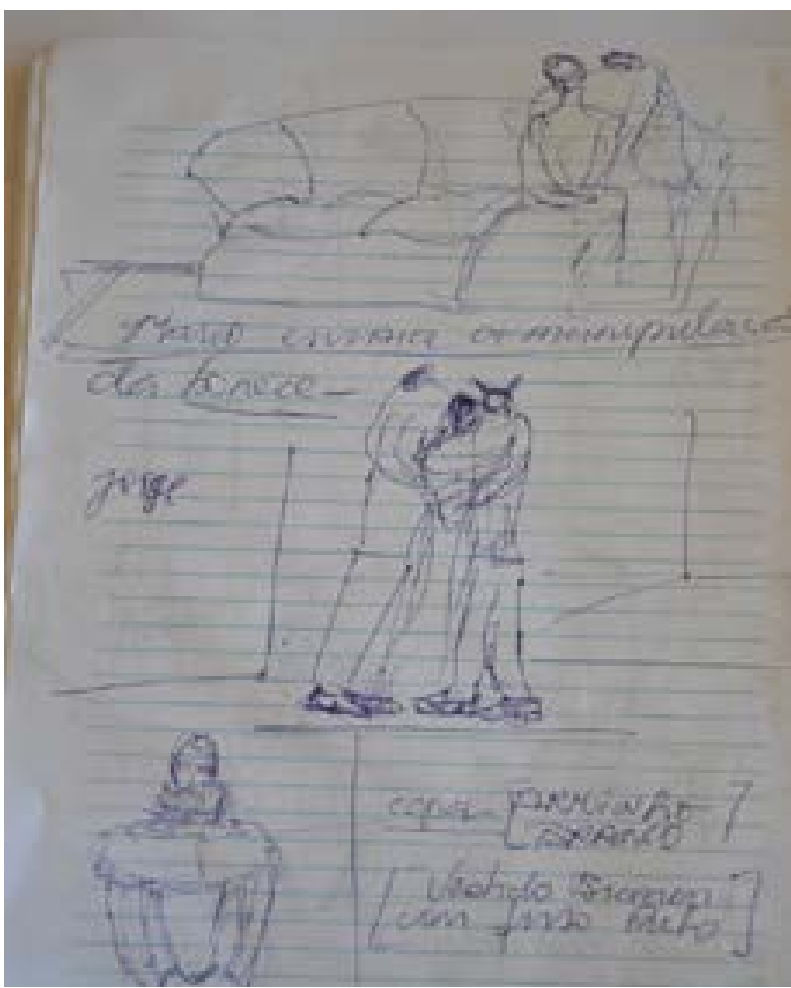

Fonte: Medeiros, 2010.

Figura 9: Sobre a cadeira.

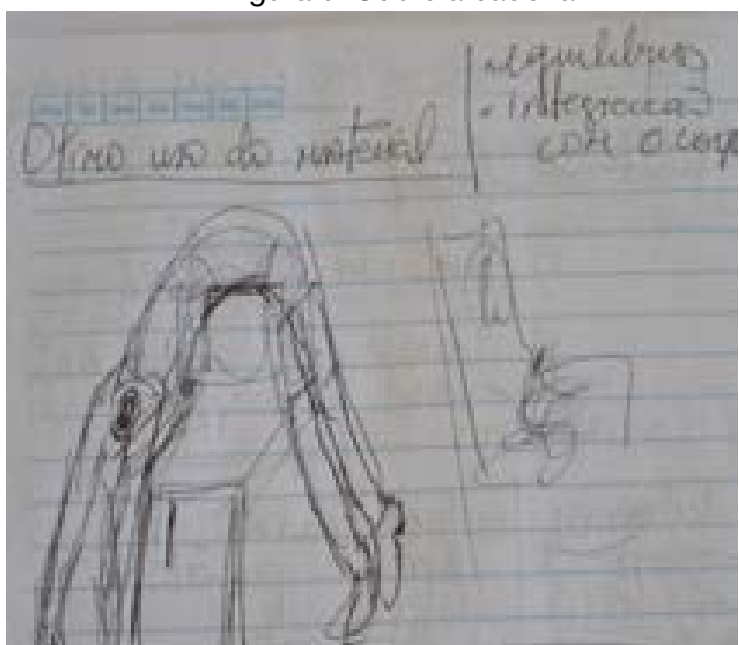

Fonte: Medeiros, 2011.
Figura 10: Agachos.

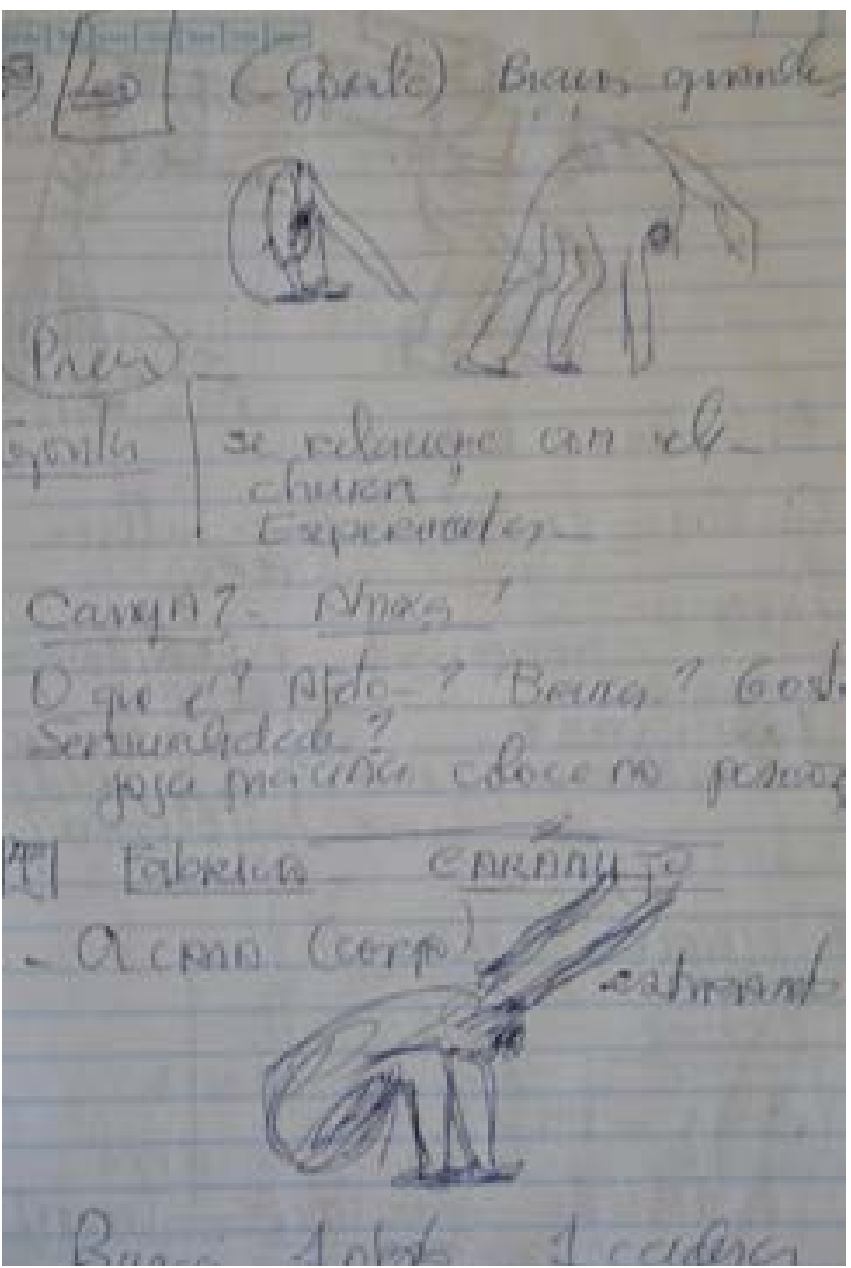

Fonte: Medeiros, 2011.

Figura 11: Apoio na mesa.

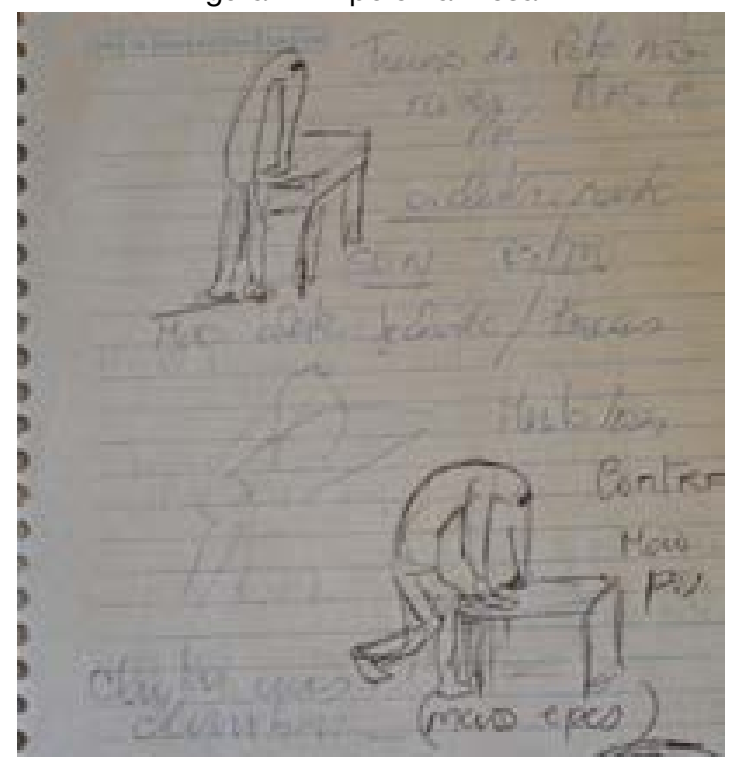

Fonte: Medeiros, 2011. 
Considerações finais: leituras do corpo desenhado

O registro de movimentos da sala de ensaio faz parte dos trabalhos de processo de lone de Medeiros e outros tantos diretores, atores, coreógrafos, artistas de dança. A prática do desenho de movimento é notória nos cadernos de artista da diretora. O desenho abre pensamentos e diálogos com teorias de outros autores, como aponta Huberman, para além de possíveis movimentos. Entretanto, esse pensamento pode ser tanto atrelado a sentimentos e constituído por ideias dos corpos e outras materialidades quanto constituído por impressões afetivas destituídas das demandas da representação. Lidar com o desenho para transformá-lo, e não recuperar o movimento que lá resta, é agir pela virtualidade que afeta o corpo. Agir pela potência afetiva que o traço porta. Pensar o corpo a partir do desenho de movimento faz parte de certa arqueologia do registro que busca aquilo que emerge e ao mesmo tempo se deposita no traço desenhado. Ausência e presença coadunadas na construção de sentido.

Os desdobramentos inventivos experimentados a partir da leitura dos desenhos se deram sob a forma de movimentos outros e reflexões sobre o corpo. Pensar a performatividade a partir da iterabilidade e da citacionalidade, como propõe Derrida, confere ao performar a transformação, uma repetição que não produz o mesmo, mas sim o diferente.

Interessante observar que o trabalho de compreensão/interpretação dos registros desenhados impõe a necessidade de se efetivarem leituras do movimento. Compreendemos as leituras como interpretações, criações sobre o que se observa. Já dissemos que essas interpretações viabilizam outros movimentos que, por sua vez, poderiam ser registrados $\mathrm{e}$ o processo de leitura inventiva reproduzido recursivamente. A leitura dos desenhos além de produzir pensamento-sentimento, proporcionou a feitura de "novos" movimentos. "Novos" porque há neles uma restância, como reforça Derrida quando diz da iterabilidade. Corpo que lê movimento, que, sem a mediação de palavras, gera mais movimento.

Assim, vimos que o estudo genético do processo pode dedicar-se a estudar os vestígios para construir outros sentidos. O caderno de artista como plataforma de pesquisa. Pesquisa-se para produzir mais material de pesquisa. Aqui interessou a performatividade dos registros, a qual permitiu partir do mesmo rumo ao diferente.

\section{Referências}

ALMEIDA, Inês B. A cegueira na origem do desenho: Jacques Derrida em Memoires D' Aveigle. Philosophica, 19/20, Lisboa, 2002, p. 155-176.

AUSTIN, John L. Quando dizer é fazer: palavras e ação. [Tradução Danilo Marcondes de Souza Filho]. Porto Alegre: Artes Médicas, 1990.

BOEHM, Gottfried. Aquilo que se mostra. Sobre a diferença icônica. In: Pensar a imagem. Emmanuel Alloa (Org.) Belo Horizonte: Autêntica Editora, 2015.

Ribeiro // O Desenho do Movimento no Processo de Criação Rev. Cena, Porto Alegre, n. 22, p. 166-176, jul./out. 2017 Disponível em: http://seer.ufrgs.br/cena 
BUDOR, Dominique; GRÉSILLON, Almuth; MERVANT-ROUX, Marie-Medeleine. Por uma Genética Teatral: Premissas e desafios. Revista Brasileira de Estudos da presença. Porto Alegre, v.3,n.2.p. 379-403, 2013.

DERRIDA, Jacques. Limeted inc. Campinas, SP: Papirus, 1991.

DIDI-HUBERMAN, George. O que vemos, o que nos olha. São Paulo: Editora 34, 1998.

FÉRAL, Josette. A fabricação do Teatro: questões e paradoxos. Revista Brasileira de Estudos da Presença. Porto Alegre, v.3, n.2. p. 566581, 2013.

KAGHAT, Fahd. Os Vestígios Manuscritos do Espetáculo: os registros de encenação. Revista Brasileira de Estudos da presença. Porto Alegre, v.3, n.2, p. 420-433, mai/ago. 2013.

SALLES, Cecília Almeida. Gesto Inacabado: processo de criação artística. São Paulo: FAPESP: Annablume, 2004.

SALLES, Cecília Almeida. Redes da criação: Construção da obra de arte. São Paulo: Editor Horizonte, 2008.

VALERY, Paul. Degas dança desenho. São Paulo: Cosac Naif, 2012.

\section{Cadernos (fonte das figuras)}

MEDEIROS, Mônica. Caderno 1C, p. 15-112130, 2010.

. Caderno 1D, p. 10- 11-13-167-193,
Recebido: 15/04/2017 Aprovado: 20/06/2017 . Caderno 1F, p. 120, 2012. . Caderno 1G, p. 285, 2012. 